\title{
Paisajes rituales nahua-pipiles del postclásico en la Costa del Bálsamo, El Salvador
}

\begin{abstract}
Resumen
Los paisajes rituales están conformados por apropiaciones, tanto físicas como simbólicas, de un espacio específico durante un período determinado. Durante los períodos epiclásico (600-850 d.C.) y postclásico (850-1524 d.C.), los nahua-pipiles protagonizaron movimientos migratorios diásporos masivos desde el altiplano central mexicano hasta las costa pacífica centroamericana. El presente artículo analiza, desde la arqueología del paisaje, los recientes descubrimientos de sitios arqueológicos postclásicos registrados en la Costa del Bálsamo, interpretando la particular geomorfología como el paisaje ritual deseado por los nahua-pipiles para evocar a sus deidades y legitimar su propia memoria histórica a través de construcciones cognitivas asociadas a su lugar de origen.
\end{abstract}

\section{Palabras clave}

Arqueología-El Salvador-Historia, arqueología Nahua-Pipil, restos arqueológicos, excavaciones arqueológicas, arquitectura antigua.

\begin{abstract}
Ritual landscapes are formed by both physical and symbolic appropriation of a particular area during a specific time period. During Epiclassic (600-850 AD) and Postclassic (850-1524 AD) periods, the Nahua-Pipil staged a massive diasporic migration from central Mexico to the Central American Pacific coast. This article analyzes, from a landscape archeology perspective, recent discoveries of Postclassic archaeological sites registered in Balsam Coast, interpreting the particularly geomorphology as the ritual landscape desired by the Nahua-Pipil in order to evoke their deities and legitimize their own historical memory through cognitive constructs associated with their homeland.
\end{abstract}

\section{Keywords}

Archaeology-El Salvador-History, Nahua-Pipil archaeology, archaeological remains, archaeological excavations, ancient architecture.

\section{Introducción}

A lo largo del tiempo, las migraciones nahua-pipiles ocurridas durante el período postclásico (850-1534 d.C.) han planteado diferentes interrogantes relacionados con las razones que motivaron a estos grupos a migrar en diferentes oleadas desde el altiplano mexicano hasta la costa pacífica centroamericana (Fowler, 1981, 1983, 1985,
1989, 2011a; Amaroli, 1992; Batres, 2009; Bruhns 1980, 1986; Bove 2002; Chinchilla, 1998; Escamilla, 2011). Dentro de los interrogantes planteados por diversos investigadores destacan la localización de sus asentamientos, las características geomorfológicas del paisaje elegido por los nahua-pipiles y los motivos socioculturales que originaron la adopción, apropiación y transformación de paisajes culturales tan particulares. Existen evidencias

\footnotetext{
1 Marlon V. Escamilla es candidato a Doctor en Antropología de la Universidad de Vanderbilt, Nashville, Tennessee. Actualmente es el coordinador de la Licenciatura en Arqueología de la Universidad Tecnológica de El Salvador.

2 William R. Fowler es Doctor en Antropología, y actualmente es profesor y catedrático de Antropología en la Universidad de Vanderbilt, Nashville, Tennessee.
} 
lingüísticas, históricas y arqueológicas que indican una fuerte migración pipil durante el posclásico temprano (850-1200 d.C.). Para este período, los asentamientos pipiles estaban distribuidos por todo el centro y oeste del actual territorio de El Salvador, lo cual podría indicar que las oleadas migratorias probablemente ocurrieron desde el período epiclásico (600-850 d.C.). En base a los registros históricos, para la época de la Conquista (1524), los grupos nahua-pipiles se encontraban localizados en el sureste de la costa Pacífica centroamericana, el sureste de las tierras altas de Guatemala y específicamente en la parte central y oeste de El Salvador.

Los asentamientos nahua-pipiles del postclásico temprano (850-1200 d.C.) poseen dos características principales: su ubicación en la parte alta de los cerros y la arquitectura amurallada; ambas características reflejan consideraciones defensivas (Fowler, 1989). Sin embargo, las razones por las cuales los grupos nahua-pipiles adoptaron esta particular geomorfología defensiva aún son ambiguas. Aunque en el pasado se han desarrollado registros esporádicos de sitios arqueológicos en la Costa del Bálsamo, la implantación de un reconocimiento arqueológico sistemático en la zona es fundamental para entender la situación sociopolítica que emergió a raíz de este movimiento poblacional. Recientes investigaciones desarrolladas en dicha área por el proyecto Migraciones nahua-pipiles del postclásico en la Cordillera del Bálsamo han permitido documentar una concentración considerable de asentamientos postclásicos. El objetivo de identificar, registrar y documentar sitios arqueológicos postclásicos, asociados a grupos nahua-pipiles, tiene como finalidad obtener y analizar datos que permitan desarrollar una perspectiva de los diferentes procesos culturales de apropiación y transformación del paisaje cultural, ocurridos como producto de un proceso de migración diaspórica durante el período postclásico.

\section{Sitios postclásicos en la Costa del Bálsamo}

El proyecto Migraciones nahua-pipiles del postclásico en la Cordillera del Bálsamo, durante la temporada de campo de 2012, se desarrolló en cuatro municipios: Teotepeque, Jicalapa, Chiltiupán y Tamanique, todos pertenecientes al departamento de La Libertad y ubicados en la Costa del Bálsamo (Fig. 1). El área de los cuatro municipios suma un total de $350 \mathrm{~km}^{2}$, aproximadamente. En base al análisis de fotografías aéreas, de mapas cartográficos, de imágenes satelitales y de los antecedentes de investigaciones en la zona, se diseñó una estrategia metodológica que permitiera optimizar recursos y, a la vez, potencializar el registro de nuevos sitios en el área.
De acuerdo con lo anterior, la estrategia metodológica se dividió en dos programas, el primero enfocado a visitar sitios arqueológicos previamente registrados con la finalidad de actualizar y obtener nuevos datos para su debido análisis, $y$ el segundo en desarrollar reconocimientos pedestres a través de transeptos, con el objetivo de registrar y documentar nuevos sitios arqueológicos en el área de estudio. En ambos programas participó un equipo de cinco estudiantes avanzados de la licenciatura en Arqueología de la Universidad Tecnológica de El Salvador (Utec): Nancy Trujillo, Julián Tolentino, Maberick Caballero, Kathy García y David Messana, con el cual se desarrollaron las visitas de campo, el mapeo de sitios, la recolección superficial de artefactos y su análisis. A continuación se presenta una breve descripción de cada uno de los sitios visitados.

\section{Cerro de Ulata}

El sitio arqueológico Cerro de Ulata se encuentra ubicado en el municipio de Teotepeque, departamento de La Libertad, en terrenos parcelados de propiedad privada y a una altura de $410 \mathrm{msnm}$ (Fig. 1). El sitio fue registrado por Jorge Lardé (1926) y mencionado por John Longyear (1944). Sin embargo, el sitio es descrito y mapeado por primera vez por los investigadores del Proyecto Izalco, interpretándolo como un asentamiento de la fase Guazapa y contemporáneo del sitio Cihuatán en base a su patrón de asentamiento y a su cerámica (Fowler, Amaroli \& Arroyo, 1989).

El sitio está conformado por al menos veinticinco montículos con una distribución espacial de las estructuras a lo largo de la bifurcación de una lengüeta en dos ejes orientados norte-sur, dicha distribución está determinada por la topografía de la cresta de la lengüeta. El sitio se divide en dos grandes concentraciones de montículos, las cuales han sido denominadas como Grupo Este y Grupo Oeste. El Grupo Este fue identificado y mapeado por el Proyecto Izalco. Dicho grupo está conformado por al menos once montículos distribuidos sobre un eje norte-sur conformando pequeñas plazas.

En base a las diferentes visitas realizadas por el equipo del Proyecto al sitio y al reconocimiento arqueológico sistemático implantado, se logró identificar una agrupación de montículos y pequeñas plazas, los cuales se denominaron como Grupo Oeste. Dicho grupo está conformado por, al menos, catorce montículos distribuidos sobre un eje norte-sur y conformando, al menos, tres pequeñas plazas. Cada uno de los montículos de ambos grupos fueron georeferenciados, mapeados y analizados en GIS. 
El sistema constructivo aparentemente está conformado por rocas volcánicas. No se logró identificar en superficie ningún tipo de repello. El terreno donde se ubica el sitio Cerro de Ulata actualmente se encuentra parcelado y tiene un uso agrícola con siembras de maíz, frijol y maicillo. Sin embargo, el Grupo Oeste presenta una pequeña concentración de construcciones habitacionales modernas. En términos de conservación, el sitio se encuentra relativamente bien conservado; a excepción del Grupo Oeste, el cual presenta saqueos en algunos montículos.

Dentro de los materiales recolectados se logró identificar material lítico, como puntas de flecha de obsidiana negra, fragmentos de manos y metates. Debido a que el sitio fue prospectado cuando el maíz y el frijol estaban crecidos, se dificultó la recolección de material. Sin embargo, se logró identificar cerámica postclásica. En términos de distribución espacial, los antiguos pobladores aprovecharon al máximo el espacio de la bifurcación de la lengüeta, lo cual sin duda alguna muestra una apropiación del paisaje con características geomorfológicas, las cuales fueron aprovechadas en términos defensivos. Aunque el sitio no ha sido excavado aún, se puede considerar que el Cerro de Ulata tuvo un uso cívico-ceremonial en el cual se desarrollaban prácticas de control y/o vigilancia, y muy probablemente asociado a prácticas ceremoniales.

\section{Letrero del Diablo}

El sitio arqueológico Letrero del Diablo se encuentra ubicado en el municipio de Jicalapa, departamento de La Libertad, y a una altura de $140 \mathrm{msnm}$ (Fig. 1). El área donde se encuentra ubicado el sitio está catalogada como área protegida por el Ministerio de Medio Ambiente y Recursos Naturales (MARN). El sitio fue registrado por Jorge Lardé (1926). Sin embargo, la ficha de registro que existe actualmente en la Dirección de Arqueología de la Secretaria de Cultura de la Presidencia (SEC) no contiene mayor información del sitio.

El Letrero del Diablo es un sitio de arte rupestre, el cual está conformado por una concentración de manifestaciones gráfico-rupestres sobre un paredón rocoso con dimensiones de $50 \mathrm{~m}$ de largo por $8.5 \mathrm{~m}$ de alto. Los petrograbados se encuentran orientados al oeste, abarcando un área de $10 \mathrm{~m}$ de largo y 2.7 de alto. En términos generales, los petrograbados presentan un estilo abstracto, destacando en su mayoría figuras geométricas y en menor porcentaje figuras antropomorfas y zoomorfas. Sin embargo, el petrograbado más relevante es la representación estilizada de Tlaloc, deidad asociada a la lluvia y el agua. Cabe destacar que el sitio se encuentra ubicado al costado este de la quebrada Iscacuyo o El Cacao. En términos de conservación, el sitio se encuentra en mal estado debido a que las incisiones de los petrograbados han sido pintados con tiza y con pintura de aceite colores rojo y blanco. Como parte del proyecto, se realizó un levantamiento fotográfico de todos los petrograbados, así como un levantamiento digital en mosaico para obtener una imagen panorámica, utilizando un GigaPan EPIC Pro. El levantamiento fue hecho con el apoyo del Dr. Fabio E. Amador, oficial de programa de National Geographic Society.

El petrograbado de Tlaloc constituye una representación importante para la interpretación del sitio. Probablemente, en el sitio Letrero del Diablo se desarrollaron prácticas rituales venerando a la deidad Tlaloc, las cuales estaban asociadas a la invocación del elemento agua. Estos rituales practicados durante el período postclásico por grupos nahua-pipiles posiblemente fueron practicados con relativa frecuencia en las partes bajas de las lengüetas, donde se ubican ríos y quebradas de invierno, tomando en cuenta que la mayoría de los sitios del complejo Guazapa ubicados en la Costa del Bálsamo se encuentran en la cresta de las lengüetas, es decir lugares en los cuales se dificulta el acceso al agua.

\section{El Panteoncito}

El sitio arqueológico El Panteoncito se encuentra ubicado en el municipio de Tamanique, departamento de La Libertad, específicamente en los terrenos de la Cooperativa San Isidro. El sitio se localiza sobre la parte alta y en el sector norte de la loma El Cabro, a una altura de 610 msnm (Fig 1). El asentamiento se encuentra delimitado hacia el norte por la prolongación de la lengüeta y por el cantón y caserío San Isidro; al sur, por la prolongación de la lengüeta. El Panteoncito se encuentra aproximadamente a $1.5 \mathrm{~km}$ al norte del sitio Miramar, sobre la misma lengüeta. El límite oeste está marcado por el final de la lengüeta, la cual desciende de 610 a $541 \mathrm{msnm}$; y el extremo este presenta una pequeña prolongación de la lengüeta, la cual posee un eje este-oeste y termina descendiendo de 610 a 400 msnm.

El sitio fue registrado por Escamilla (2011) y está conformado por veintiuna estructuras, las cuales se encuentran divididas en siete grupos de montículos. La distribución espacial de las estructuras se da a lo largo de la bifurcación de una lengüeta en dos ejes: uno largo orientado norte-sur y uno corto orientado este-oeste; ambos ejes forman una L invertida, la cual está determinada por la topografía de la lengüeta. El grupo $A$, ubicado en el límite norte, presenta tres montículos (M1-M3) distribuidos sobre una plataforma, formando una plazuela. El grupo B, ubicado en el límite este, se compone de dos montículos (M13-M14), formando 
una plazuela. El grupo $\mathrm{C}$ se encuentra ubicado sobre el eje norte-sur y está conformado por tres montículos (M4M6), los cuales forman una pequeña plaza. El grupo D, ubicado sobre el eje norte-sur, está compuesto por cuatro montículos (M7-M10), formando una plazuela. El grupo E se encuentra ubicado sobre el eje norte-sur y está conformado por dos montículos construidos sobre una plataforma, formando una pequeña plaza. Aproximadamente a 0.5 $\mathrm{km}$ al norte del grupo $\mathrm{E}$, siempre sobre el eje norte-sur, se encuentran los grupos F y G. El grupo F está conformado por tres montículos (M15-M17), formando una pequeña plaza. Finalmente, el grupo G marca el límite sur del sitio y está compuesto por cuatro montículos (M18-M21), formando una pequeña plaza.

La anterior descripción espacial se realizó con los datos recolectados durante el reconocimiento arqueológico desarrollado en la temporada de campo del 2010. Sin embargo, el reconocimiento arqueológico sistemático implantado por el equipo del proyecto en la temporada 2012, logró identificar una nueva concentración de montículos y pequeñas plazas al extremo sur del sitio. Los nuevos datos recolectados en campo permitieron identificar todo un grupo de concentración de montículos, el cual fue denominado como Grupo Sur. Este grupo está conformado por al menos doce montículos distribuidos sobre un eje norte-sur sobre una planicie a $610 \mathrm{msnm}$ y conformando, al menos, tres pequeñas plazas. Cada uno de los montículos fueron georeferenciados, mapeados y analizados en GIS. En su mayoría, los montículos son bajos, con alturas oscilando entre 0.5 y $1.5 \mathrm{~m}$. El sistema constructivo, aparentemente, está conformado por rocas volcánicas. No se logró identificar en superficie ningún tipo de repello. Debido a que el terreno donde se ubica el sitio El Panteoncito le pertenece a la Cooperativa San Isidro, el uso de la tierra actualmente es agrícola, con siembras de maíz y frijol y maicillo. En términos de conservación, el sitio se encuentra relativamente bien conservado. Dentro de los materiales recolectados se logró identificar material lítico, como puntas de flecha de obsidiana negra, fragmentos de manos y metates. Acerca de la cerámica, se logró identificar algunos tiestos del tipo cerámico Las Lajas.

En total, sumando los grupos Norte y Sur, el sitio El Panteoncito está conformado por veintinueve montículos. En términos de distribución espacial, es impresionante cómo los antiguos pobladores aprovecharon al máximo la cresta de la lengüeta y su angosto espacio. Algunos trayectos de la lengüeta no superan los 20 m en su eje esteoeste. Probablemente El Panteoncito fungió como un sitio cívico-ceremonial, en el cual se desarrollaban prácticas rituales, ejerciendo control, vigilancia y poder político.
Así mismo, es probable que el sitio fuese utilizado como área habitacional restringida para miembros de la elite, quienes controlaban diversas prácticas culturales, tales como prácticas religiosas asociadas a rituales y prácticas agrícolas y de control de comercio.

\section{Zinacantan}

El sitio arqueológico de Zinacantán se encuentra ubicado en el municipio de Tamanique, departamento de La Libertad, específicamente sobre la parte alta del Cerro Pueblo Viejo, a una altura de $460 \mathrm{msnm}$ (Fig. 1). El asentamiento se encuentra delimitado hacia el norte por la prolongación de la lengüeta y por el cantón y caserío Tarpeya; al sur, por el Cerro Redondo o Peñol de Zinacantán. El límite este se marca por el final de la lengüeta, la cual desciende de 460 a 250 msnm hasta la Quebrada La Joyona o El Tacuacín; y el extremo oeste está marcado por el final de la lengüeta, la cual desciende de 460 a 250 msnm hasta la quebrada Pozo Hondo.

El sitio fue descubierto por William R. Fowler en 1989, mientras dirigía el Proyecto Los Izalcos, desarrollando reconocimientos arqueológicos. Fowler escuchó de la existencia de un sitio arqueológico en Pueblo Viejo, jurisdicción de Tamanique, llamado Zinacantán. Posteriormente, el sitio fue visitado y registrado por William Fowler, Roberto Gallardo y Conard Hamilton (Hamilton, 2009). Durante el año 2001 y 2002, el sitio fue georeferenciado y mapeado con un estación total electrónica por Conard Hamilton.

Hamilton (Ibíd.) dividió a Zinacantán en tres sitios. El sitio 1 está conformado por ocho montículos distribuidos sobre la angosta lengüeta y formando al menos dos pequeñas plazas. El sitio 2, ubicado al extremo sur de la lengüeta, está conformado por siete montículos distribuidos, formando al menos tres pequeñas plazas y delimitados por una pared baja construida al contorno de la estrecha lengüeta. El sitio 3, ubicado al extremo norte, está conformado por once montículos, formando al menos dos plazas. En total, Zinacantán contiene al menos veintiséis montículos, constituyendo uno de los sitios con mayor número de estructuras registradas hasta el momento en la Costa del Bálsamo. De acuerdo con el análisis cerámico hecho por Hamilton, el sitio probablemente tenga ocupación postclásica tardía. Sin embargo, no se puede descartar que Zinacantán sea un sitio que posea una ocupación permanente desde el postclásico temprano hasta el tardío.

El segundo programa constituyó en un reconocimiento sistemático pedestre, el cual se desarrolló en la mayoría de los casos sobre la cresta de las lengüetas, y en 
algunos casos puntuales sobre las pendientes y las pequeñas planicies que se forman entre las lengüetas. El reconocimiento arqueológico se implantó en los municipios de Teotepeque, Jicalapa, Chiltiupán y Tamanique (Fig. 1), posterior a un análisis previo de fotos aéreas, imágenes satelitales, análisis cartográfico de la geomorfología del área de estudio y antecedentes de sitios registrados en la zona.

Como resultados directos del reconocimiento arqueológico desarrollado por el equipo del proyecto, destacan la identificación de tres sitios nuevos, de los cuales no se tenía registro de su existencia previo a la ejecución de dicho proyecto. Los sitios arqueológicos fueron denominados como: Caballito, Texisio y El Letrero (Fig. 2). Cada uno de los sitios fue georeferenciado, mapeado y analizado a través del sistema GIS. A continuación se presenta una breve descripción de los sitios registrados.

\section{Caballito}

El sitio arqueológico Caballito se encuentra ubicado en el municipio de Teotepeque, departamento de La Libertad, específicamente sobre la parte alta de la Loma del Caballito, a una altura de $500 \mathrm{msnm}$ (Fig. 1). El asentamiento se encuentra localizado en terrenos propiedad de la Cooperativa Chiquileca. Actualmente el sitio está delimitado hacia el norte por la prolongación de la lengüeta y al sur por la Loma Los Encuentros. El límite este está marcado por el río Mizata, donde la lengüeta desciende de 500 a 150 msnm; y el extremo oeste está marcado por el final de la lengüeta, la cual desciende de 500 a 259 msnm hasta la quebrada El Tambor. El sitio fue descubierto y registrado por el autor, durante el desarrollo del proyecto. Durante varias visitas al sitio, se logró georeferenciar cada uno de los montículos y mapear el sitio con brújula y cinta métrica. Así mismo, se realizó una recolección superficial sistemática de materiales culturales.

El sitio Caballito está conformado por diez montículos distribuidos en dos concentraciones, las cuales se denominaron como Grupo Norte y Grupo Sur. El primero está constituido por cuatro montículos, los cuales conforman una pequeña plaza. El Grupo Sur está conformado por seis montículos, los cuales están orientados sobre un eje noreste-suroeste y separado en grupos de dos, conformando, al menos, tres pequeñas plazas. En el límite sur del sitio se logró identificar una pequeña área quemada, formando terrones aproximadamente del tamaño de un puño. Es difícil establecer si esta huella de quema esté asociada a prácticas desarrolladas en tiempos prehispánicos o se deba a prácticas agrícolas actuales. Lo anterior se logrará determinar solamente a través de un programa de excavaciones en el área.

El sistema constructivo, aparentemente, está conformado por rocas volcánicas. No se logró identificar en superficie ningún tipo de repello. Actualmente el uso de la tierra es agrícola, algunas parcelas se encuentran sembradas con maíz, frijol y maicillo, otras no presentan siembra alguna. En términos de conservación, el sitio se encuentra relativamente bien conservado.

Dentro de los materiales recolectados se logró identificar cerámica asociada al complejo Guazapa, material lítico, como puntas de flecha de obsidiana negra, fragmentos de manos y metates con una relativa abundancia. En términos de distribución espacial, el sitio fue construido sobre la bifurcación de una lengüeta, lo cual es interesante debido a que sitios como El Panteoncito y Cerro de Ulata presentan el mismo patrón de asentamiento. Caballito se puede considerar como un sitio habitacional del complejo Guazapa, en el cual probablemente se desarrollaban prácticas de control o vigilancia.

\section{Texisio}

El sitio arqueológico Texisio se encuentra ubicado en el municipio de Teotepeque, departamento de La Libertad, específicamente sobre la parte alta de la lengüeta Texisio a una altura de $281 \mathrm{msnm}$ (Fig. 1). El asentamiento se encuentra localizado en terrenos privados. Actualmente el sitio está delimitado hacia el norte por la Loma El Cerro; al sur, por el final de la lengüeta. El límite este está marcado por la quebrada de Texisio donde la lengüeta desciende de 281 a 50 msnm; y el extremo oeste está marcado por el final de la lengüeta, la cual desciende de 281 a 29 msnm hasta el río Mizata.

El sitio fue descubierto y registrado por el autor durante el desarrollo del proyecto. Durante las visitas al sitio se logró georeferenciar cada uno de los montículos y mapear el sitio con brújula y cinta métrica. Así mismo, se realizó una recolección superficial sistemática de materiales culturales.

El sitio Texisio está conformado por tres montículos, los cuales forman una plaza. El sistema constructivo, aparentemente, está conformado por rocas volcánicas. No se logró identificar en superficie ningún tipo de repello. Actualmente el uso de la tierra es agrícola, el área se encuentra sembrada de pasto y existen construcciones habitacionales modernas en muy baja densidad. En términos de conservación, el sitio se encuentra bien conservado. Dentro de los materiales recolectados se 
logró identificar cerámica asociada al complejo Guazapa, material lítico, como puntas de flecha y navajas prismáticas de obsidiana negra.

\section{El Letrero}

El sitio arqueológico El Letrero se encuentra ubicado en el municipio de Chiltiupán, departamento de La Libertad, específicamente en la Finca Guadalupe Arriba del cantón y caserío Cuervo Abajo, y a una altura de 400 msnm (Fig. 1). Actualmente el sitio está delimitado hacia el norte por la Finca Guadalupe Arriba, al sur por el río El Zonte. El límite este es marcado por el río Pájaro León; y el extremo oeste está marcado por el río El Zonte. El sitio fue descubierto y registrado por el autor durante el desarrollo del proyecto. Durante las visitas se logró georeferenciar el sitio y realizar un levantamiento digital fotográfico de las manifestaciones gráfico-rupestres.

El Letrero es un sitio de arte rupestre, el cual está conformado por una concentración de manifestaciones gráfico-rupestres sobre una roca con dimensiones de $15 \mathrm{~m}$ de largo por 12 de alto. Los petrograbados se encuentran orientados al este, abarcando un área de $3 \mathrm{~m}$ de largo y 2 de alto. En términos generales, los petrograbados presentan un estilo abstracto, destacando en su mayoría figuras geométricas, como círculos concéntricos y espirales, así como una concentración de cúpulas. Aunque en menor porcentaje, se lograron registrar figuras antropomorfas y zoomorfas. Sin embargo, el petrograbado más relevante es la representación estilizada de un Tlaloc, deidad asociada a la lluvia y el agua. Cabe destacar que el sitio se encuentra ubicado en el punto de convergencia de los ríos Pájaro León y El Zonte. Aproximadamente a $200 \mathrm{~m}$ al norte de la roca con los petrograbados se registró una pequeña plataforma rectangular, la cual muy probablemente sirvió como altar durante las prácticas rituales desarrolladas en tiempos prehispánicos.

Como parte del proyecto, se realizó un levantamiento fotográfico digital de todos los petrograbados. En términos de conservación, el sitio se encuentra en mal estado debido a que las incisiones de los petrograbados han sido pintadas con tiza y algunos petrograbados presentan daños de fractura, incluyendo un porcentaje de Tlaloc.

El petrograbado de Tlaloc constituye una representación importante para la interpretación del sitio. Probablemente, en el sitio El Letrero se desarrollaron prácticas rituales venerando a la deidad Tlaloc, las cuales estaban asociadas a la invocación del elemento agua. Estos rituales desarrollados durante el período postclásico por grupos nahua-pipiles posiblemente fueron practicados con relativa frecuencia en las partes bajas de las lengüetas, donde se ubican ríos y quebradas de invierno, tomando en cuenta que la mayoría de los sitios del complejo Guazapa ubicados en la Costa del Bálsamo se encuentran ubicados en la cresta de las lengüetas, es decir, son lugares en los cuales se dificulta el acceso al agua.

\section{Paisajes rituales y apropiaciones simbólicas de la Costa del Bálsamo}

El concepto de paisaje, en arqueología, es interpretado como el producto de diversos factores sociales y de agencia humana. A diferencia de la percepción del paisaje como un rasgo natural, la arqueología del paisaje interpreta al paisaje mismo como una construcción cultural. En relación con el concepto de paisaje, existen diferencias ontológicas entre los investigadores que interpretan al paisaje como una entidad independiente al ser humano y aquellos que interpretan al paisaje como una construcción a través de la agencia del ser humano (Preucel \& Hodder, 1996).

El paisaje cultural de la Costa del Bálsamo, durante el postclásico, reunía características geomorfológicas y simbólicas relevantes, las cuales fueron determinantes para establecer asentamientos pipiles. Knapp y Ashmore (1999) enfatizan las diferencias en el uso del concepto de paisaje en arqueología como una transición de la conceptualización del paisaje, como algo pasivo, a una percepción activa que va más allá de una entidad compleja relacionada con el diario vivir de los seres humanos.

El enfoque teórico de la arqueología del paisaje se basa en la idea de que los seres humanos construyen y transforman su medio ambiente de una manera fundamental. Estas manifestaciones de adopción y transformación del paisaje, en algunos casos, son el producto de procesos migratorios y de apropiaciones simbólicas de lugares y espacios deseados. En este sentido, la antropología del movimiento constituye una valiosa herramienta teórica, ya que explora el movimiento desde una perspectiva antropogénica del paisaje. El movimiento a través del paisaje incluye un vasto espectro de experiencias humanas relacionadas con diferentes percepciones del mundo y con diferentes estrategias diarias de acción y reacción. Con la finalidad de delimitar y perfilar el concepto de paisaje en arqueología, Kurt Anschuetz (2001) plantea cuatro premisas, las cuales están interrelacionadas y proveen las fundaciones principales del paradigma del paisaje: a) los paisajes no son sinónimos de los ambientes naturales. ¿Qué significa esto? Significa que los paisajes son sintéticos, son sistemas culturales estructurados, y a la vez organizan las interacciones del 
ser humano con su medio ambiente. Knapp y Ashmore (1999) agregan que el paisaje actúa como mediación entre naturaleza y cultura, y a la vez forman una parte integral del habitus conceptualizado por Bourdieu (1977); b) los paisajes son productos culturales. Cosgrove (1985) enfatiza que el paisaje no es necesariamente el mundo que vemos y percibimos, sino es una construcción, una composición de aquel mundo. Por lo tanto, paisaje no es lo mismo que construcciones ambientales, las cuales se refieren a construcciones físicas, las cuales han sido diseñadas; c) los paisajes son arenas para las diferentes actividades sociales y comunales. Por lo tanto, los paisajes no solamente son construcciones humanas, sino también son todas las condiciones ambientales en las cuales las poblaciones sobreviven y se sostienen a sí mismas; d) los paisajes son construcciones dinámicas en las que cada comunidad y cada generación impone su propio mapa cognitivo en su mundo antropogénico de morfología, planes y significación coherente, todo interconectado. El paisaje es entendido como un sistema para la manipulación de significados simbólicos en las acciones humanas y su materialidad. Por lo tanto, el paisaje es un proceso cultural.

La perspectiva del paisaje constituye un paradigma de mucha aplicabilidad en la interpretación arqueológica, el cual permite explorar diversas interpretaciones relacionadas con las prácticas y conductas de antiguas sociedades. En la actualidad, solamente algunas investigaciones arqueológicas han logrado desarrollar una aproximación teórica desde una perspectiva de paisaje con relación a como los nahua-pipiles percibieron e interactuaron con los espacios, los lugares y los paisajes durante el postclásico en El Salvador (Sampeck, 2007; Fowler, 2011b; Escamilla, 2011). Sin embargo, existen restos arqueológicos y documentación histórica que evidencian que el paisaje del actual territorio occidental de El Salvador, para finales del siglo XVI, era producto de redes sociales económicas y simbólicas del nahua-pipil prehispánico. La perspectiva del paisaje intenta abrir nuevas corrientes de interpretación que permitan interrelacionar lo material, lo social y lo ideológico en relación con la apropiación de espacios y paisajes.

Los paisajes rituales están conformados a través de la apropiación física, imaginaria y simbólica de un espacio específico durante un tiempo determinado, en los cuales se desarrollaron diversas dinámicas de prácticas sociales (Montero, 2008). Las apropiaciones de un paisaje determinado permiten a los grupos culturales desarrollar perspectivas particulares, legitimando su territorio, su memoria histórica, su prestigio y su poder. Por lo tanto, las prácticas rituales no están limitadas a desarrollarse en las montañas o cerros más altos. Cada superficie elevada ofrece múltiples escenarios, los cuales fueron interpretados en tiempos prehispánicos como lugares para evocar a deidades (Arreola \& Murillo, 2011). Así mismo, existen construcciones cognitivas en los grupos emigrantes en la búsqueda de paisajes específicos para asentarse. Dentro de estas construcciones cognitivas destacan tres causalidades, las cuales se interrelacionan entre sí: la gestación, el pasaje y el arribo a entornos que contienen remembranzas o evocaciones del lugar de origen (García, 2006).

Los nuevos datos arqueológicos obtenidos a través del proyecto permiten corroborar un patrón cultural de apropiación del paisaje durante el postclásico temprano, en el cual los grupos nahua-pipiles se encontraban adoptando y construyendo sus asentamientos en las angostas planicies de las crestas del sistema de lengüetas de la Costa del Bálsamo (Escamilla, 2011). Con respecto a las razones socioculturales que originaron la adopción, apropiación y transformación del particular paisaje, se apoya la hipótesis sugerida por Hamilton (2009) y planteada por Escamilla (2011), la cual postula dos posibles interpretaciones del porqué los nahua-pipiles decidieron asentarse en la cresta de las lengüetas de dicha costa: una asociada a motivos defensivos y otra asociada a motivos rituales y simbólicos. Probablemente los nahua-pipiles, en su proceso migratorio, encontraron en la geomorfología de las lengüetas de la Costa del Bálsamo el paisaje ritual deseado para evocar a sus deidades y legitimar su propia memoria histórica a través de construcciones cognitivas asociadas a su lugar de origen.

\section{Consideraciones finales}

Los movimientos migratorios protagonizados por los nahuapipiles durante los períodos epiclásico (600-850 d.C.) y postclásico (850-1524 d.C.) probablemente estuvieron asociados a una migración diaspórica. Las correlaciones arqueológicas están asociadas a la dispersión y aparición de cultura material, tanto de grupos cerámicos como de estilos arquitectónicos característicos del complejo Guazapa. Lo anterior permitió a los nahua-pipiles mantener una fuerte conciencia de grupo étnico a través de la memoria colectiva y el mito acerca del lugar de origen. Según los datos obtenidos en los recientes descubrimientos de sitios arqueológicos postclásicos registrados en la Costa del Bálsamo, se propone que esta área fue escogida por los nahua-pipiles como el lugar idóneo para el desarrollo de apropiaciones del paisaje en términos defensivos y simbólicos, como parte de un proceso de emulación, con la finalidad de conservar sus prácticas culturales identitarias. 
Las características defensivas que ofrece la topografía de la Cordillera del Bálsamo son obvias, las cuales pudieron ser explotadas por los grupos nahua-pipiles desde una perspectiva militarista, adoptando lugares estratégicamente defensivos como las crestas de las lengüetas. Como ejemplo, se pueden mencionar los sitios Caballito, Cerro de Ulata, Texisio, Jicalapa, Panteoncito, Miramar y Zinacantán (Fig. 1), los cuales en su totalidad se encuentran ubicados en áreas estratégicamente defensivas en su mayoría, con un control visual de $360^{\circ}$ y, en algunos casos, con restos de construcciones de cimientos de posibles paredes, como por ejemplo Zinacantán. Las extremas características defensivas de estos sitios hacen suponer una actividad sociopolítica hostil en la cual los nahua-pipiles establecieron sus prácticas culturales.

Por otro lado, la ubicación y distribución espacial de los asentamientos puede estar asociada a una posible connotación simbólica y ritual que los grupos nahua-pipiles aprovecharon del paisaje de la Costa del Bálsamo. En este sentido, los sitios El Letrero del Diablo y El Letrero son particularmente importantes debido a los petrograbados que exhiben una representación estilizada de Tlaloc, la deidad asociada al agua y la lluvia, y la ubicación de los sitios asociada a contextos acuáticos como ríos y quebradas. Así mismo, los sitios Caballito, Cerro de Ulata, Panteoncito y Zinacantán poseen una distribución espacial que sugiere que la ocupación de los asentamientos no solamente fue habitacional, sino que pudo estar relacionada con funciones de sitio rector cívico-ceremonial desde el cual la elite controlaba tanto las prácticas políticas-ceremoniales como las comerciales. Probablemente la apropiación y modificación de este tipo de paisaje de altura esté asociada a una emulación simbólica de los grupos nahua-pipiles con relación a su lugar de origen, el altiplano central mexicano, con el objetivo de preservar su identidad y desarrollar prácticas culturales que los diferenciaran de los demás grupos culturales contemporáneos a ellos.

\section{Anexos}

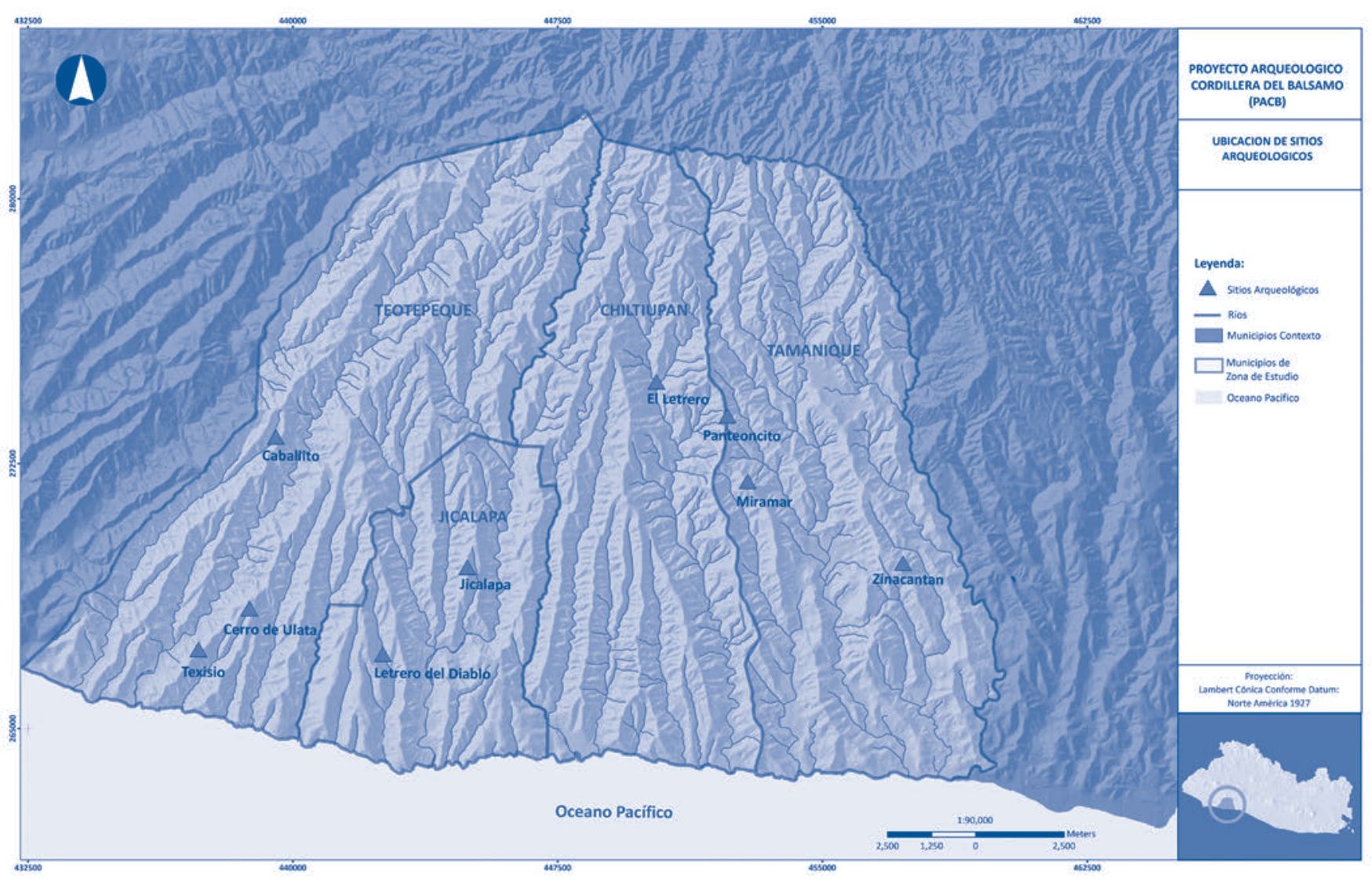

Figura 1. Ubicación del área de estudio y sitios arqueológicos. 


\section{Referencias bibliográficas}

Amaroli, P. (1992). Linderos y geografía económica de Cuscatlán, provincia pipil del territorio de El Salvador. Mesoamérica, 21, 41-70.

Anschuetz, K. Wilshusen, R. \& Scheick, C. (2001). An archaeology of landscape: perspectives and directions. Journal of Archaeological Research 9, 157-211.

Arreola, D. \& Murillo. O. (2011). Tiempo-espacio sacro en la montaña prehispánica. En Chávez, M. \&

Cabrera R. (Ed.), Moradas de Tlaloc. Arqueología, historia y etnografía sobre la montaña. México: Instituto Nacional de Antropología e Historia.

Batres, C. (2009). Tracing the "Enigmatic" Late Postclassic nahua-pipil (A.D. 1200-1500): Archaeological study of Guatemalan south pacific coast, (Tesis inédita de maestría). Southern Illinois University, Carbondale, USA.

Bourdieu, P. (1977). Outline of a Theory of Practice. New York: Cambridge University Press.

Bove, F. (2002). The Archaeology of Late Postclassic Settlements on the Guatemala Pacific Coast. En Love, M., Hatch, M. \& Escobedo, H. (Ed.), Incidents of Archaeology in Central America and Yucatan: Essays in Honor of Edwin M, Shook (179-216). Lanham: University Press of America.

Bruhns, K. (1980). Cihuatan: An early postclassic town of El Salvador: The 1977-1978 excavations. Columbia: University of Missouri Monographs in Anthropology No. 5. (1986). The Role of Commercial Agriculture in Early Postclassic Developments in Central El Salvador: The Rise and Fall of Cihuatan. En Urban, P. \& Schortman, E. (Ed.), The Southeast Maya Periphery (296-312). Austin: University of Texas Press.

Chinchilla, O. (1998). Pipiles y cakchiqueles en cotzumalguapas: La evidencia etnohistórica y arqueológica. Anales de la Sociedad de geografía de Historia de Guatemala 73, 143-184.

Cosgrove, D. (1985). Prospect, perspective and the evolution of the landscape idea. Transactions of the Institute of British Geographers 10, 45-62.

Escamilla, M. (2011). La costa del Bálsamo durante el postclásico temprano (900-1200 d.C.): Una aproximación al paisaje cultural nahua-pipil. La Universidad 14-15, 67-89.

Fowler, W. (1981). The Pipil-Nicarao of Central America., (Tesis doctoral). University of Calgary, Calgary, Cánada.
(1983). La distribución prehistórica e histórica de los pipiles. Mesoamérica 6, 348-372.

(1985). Ethnohistoric Sources on the Pipil-Nicarao of Central America: A Critical Analysis. Ethnohistory 32, 37-62.

(1988). La población nativa de El Salvador al momento de la conquista española. Mesoamérica 15, 79-116.

(1989). The Cultural Evolution of Ancient Nahua Civilizations: the Pipil-Nicarao of Central America. Norman: University of Oklahoma Press.

(2011a). El complejo Guazapa en El Salvador: La diáspora tolteca y las migraciones pipiles. La Universidad 14$15,17-66$

(2011b). Ciudad Vieja. Excavaciones, arquitectura y paisaje cultural de la primera villa de San Salvador. San Salvador: Editorial Universitaria (UES).

Fowler, W.; Amaroli, P. \& Arroyo, B. (1989). Informe preliminar del proyecto Izalco. Temporada 1988. Informe inédito preparado para la Administración del Patrimonio Cultural, El Salvador. San Salvador.

García, A. (2006). Paisaje mítico y paisaje fundacional en las migraciones mesoamericanas. Cuernavaca: Universidad Autónoma del Estado de Morelos.

Hamilton, C. (2009). Intrasite variation among household assemblages at Ciudad Vieja, El Salvador, (Tesis doctoral). Tulane University, New Orleans, USA.

Knapp, A. \& Ashmore, W. (1999). Archaeological Landscapes: Constructed, Conceptualized, Ideational. En Ashmore, W. \& Knapp, B. (Ed.) Archaeologies of Landscape: Contemporary Perspectives, (1-32). Oxford: Blackwell.

Lardé, J. (1926). Índice provisional de los lugares del territorio salvadoreño en donde se encuentran ruinas y otros objetos de interés arqueológico. Revista de Etnología, Arqueología y Lingüística 1, 281-286.

Longyear, J. (1944). Archaeological Investigations in El Salvador. Cambridge: Memoirs of the Peabody Museum of Archaeology and Ethnology 9 (2), Harvard University.

Montero, I. (2008). Apuntes al mapa de Cuauhtinchan II desde la geografía simbólica. En Tucker, T. \&

Montero, I. (Ed.) Mapa de Cuauhtinchan II. México: Mesoamerican Research Foundation.

Preucel, R. \& Hodder, I. (1996). Nature and Culture. En Preucel, R. \& Hodder, I. (Ed.), Contemporary Archaeology in theory: A reader (23-38). Oxford: Blackwell.

Sampeck, K. (2007). Late Postclassic to colonial landscape and political economy of the Izalcos region, El Salvador, (Tesis doctoral). Tulane University, New Orleans, USA. 